science Education, 2016. Vol. 11. № 8 P. 2113-2122. DOI: https://doi.org/ 10.12973/ijese.2016.582a

3. Jessica Mansbach. Using technology to develop students' critical thinking skills. URL: https://dl.sps.northwestern.edu/blog/2015/09/usingtechnology-to-develop-students-critical-thinking-skills (date of application 16.02.2021)

4. Sammy Ekaran. 8 Ways To Improve Your Critical Thinking With Technology. URL: http://blog.whooosreading.org/8-ways-to-improve-yourcritical-thinking-with-technology (date of application 15.02.2021)

DOI https://doi.org/10.30525/978-9934-26-039-1-98

\title{
УНИВЕРСАЛЬНОСТЬ - КЛЮЧЕВОЕ ТРЕБОВАНИЕ СОВРЕМЕННОГО ОБУЧЕНИЯ ИНОСТРАННЫМ ЯЗЫКАМ
}

\author{
Парфимович О. В. \\ магистр, \\ преподаватель кафедры перевода \\ Донеикого института сочиального образования \\ 2. Киев, Украина
}

Шолохов А. В.

кандидат физико-математических наук, дочент кафедры прикладных информационных систем Киевского наџионального университета имени Тараса Шевченко 2. Киев, Украина

Современный мир предъявляет жесткие требования к выпускнику любого высшего учебного заведения, а, значит, есть над чем задуматься и что совершенствовать в системе обучения студентов старших курсов, чтобы они, выйдя из стен альма-матер, могли найти перспективную работу на конкурентном рынке труда.

Проанализировав функции, объемы, которые выполняют переводчики на предприятиях, в организациях, частных компаниях и бюро переводов, а также тематики, с которыми сталкивается переводчик даже в пределах одного предприятия, становится очевидным, что работодатель стремится получить универсального, а не узкоспециализированного работника. Поэтому для подготовки такого специалиста уже в процесс обучения в вузе необходимо введение аудиторных часов для 
изучения теории и практики перевода по различным сферам экономической деятельности человека (медицины, геологии, юриспруденции, техники, металлургии, экономики и др.) при обучении иностранным языкам на старших курсах институтов и университетов.

Для удобства подачи лекционно-практического материала мы ввели термин «блочность», который является ничем иным как структурой подачи материала, а именно делением материала на блоки при обучении. Блочность подразумевает определенное количество материала, рассчитанное на определенное количество часов для изучения особенностей перевода текстов по одной тематике. Исследовав рынок переводческих услуг, мы выделили несколько направлений перевода, которые наиболее перспективны и востребованы, а именно юридическое, медицинское, техническое, геологическое и банковское (финансовое) направление. Здесь также можно сделать оговорку. Вуз может самостоятельно выбирать направление и уделять большее внимание изучению особенностей перевода определенного направления и с большим количеством часов, если в регионе, где находится вуз, развита какая-либо отрасль на высоком уровне (например, металлургическая отрасль, нефтегазодобывающая отрасль и пр.). Отдельный блок с небольшим количеством часов мы бы выделили на особенности перевода стандартных документов (ввиду несложности темы возможно изучение в части юридического блока). Блок подачи материала разбивается на такие подблоки: 1) общие особенности научно-технического перевода (по последующим блокам идет как повторение); 2) особенности конкретного направления перевода; 3) практическое применение полученных знаний (практические задания и упражнения на отработку полученных навыков). В блок можно и нужно вводить повторение грамматических тем, языковых конструкций и оборотов перед выполнением практических заданий.

В процессе обучения также не вызывает сомнений необходимость использования «перекрестной» многозначности при изучении лексики из различных сфер экономической деятельности человека. Мы специально ввели слово «перекрестная», чтобы подчеркнуть необходимость заострения внимания студентов на том, что одно и то же слово, но в разных тематических направлениях будет переводиться поразному. Т.е. идет перекрещивание тематик и, как следствие, студент не привязывается к одному переводу такого слова, возможно, даже из общей лексики, как единственно возможному варианту перевода. В памяти обучаемого будет откладываться посыл на многозначность слова с учетом особенности применения в различных тематиках.

Отдельным пунктом мы хотим выделить необходимость поддержания интереса студентов к развитию письменной речи и работе 
со словарями, ведь при работе с письменной составляющей задания включается механическая, зрительная память. Применение информационных технологий в сфере перевода приводит к тому, что у обучаемого появляется иллюзия легкости осуществления перевода: программа выбирает слова, конструкции, обороты, грамматическое время. Полное перекладывание переводчиком своих функциональных обязанностей на технические средства перевода приводит в итоге к растущему непрофессионализму и снижению качества перевода. Человеку, который часто использует и полагается только на машинный перевод, как правило, тяжело проверить правильность и точность перевода, как постмашинного, так и выполненного человеком. Поэтому работа с карточками, письменная обработка текста, отработка синонимического ряда слов в аудиторных условиях, должна быть неотъемлемой частью процесса обучения. Задача вузов выпустить из своих стен не просто слушателя курсов иностранных языков, а специалиста. Работа со словарями, блиц-сочинения и письменные блии-переводы должны стать рабочими инструментами при подготовке лингвистов, ограничивающими факторами в применении студентами средств «быстрого» перевода, возможном в условиях самостоятельной внеаудиторной работы. В этом плане следует учитывать, что при использовании таких рабочих инструментов увеличивается нагрузка на преподавателя. Отсюда возникает и еще один вопрос о том, кто должен вести такой курс «блочных» занятий в высших учебных заведениях. Преимущество, по нашему мнению, в этом случае имеют переводчики-практики со стажем работы по различным направлениям перевода не менее десяти лет.

В заключение представляем кратко модель блочного изучения и отработки навыков перевода текстов по медицинской геологии, как одного из новых направлений научного перевода.

Первый подблок рассматривает общие особенности научно-технического перевода. Это теоретическая часть, которая знакомит обучаемого с лексическими трудностями научно-технического перевода: многозначностью, синонимией, неологизмами, «ложными друзьями» переводчика, иностранными заимствованиями, использованием переводческих трансформаций в научно-технических текстах (перестановки, замены, добавления, опущения), а также дает общую характеристику научно-технического языка: отсутствие эмоциональной окрашенности, стремление к ясности, четкости и краткости, иностранные заимствования, редкость переносных и контекстуальных значений, частотность употребления и относительная важность некоторых грамматических форм и конструкций (использование Passive Voice, препозиционное положение существительного в роли определения и др.), 
редкость употребления идиоматических выражений, применение сокращений и условных обозначений [2, с. 23-27].

Второй подблок включает раскрытие особенностей конкретного направления перевода; Язык перевода текстов медико-геологической направленности отличается тем, что в нем содержится большое количество научных названий из греческого языка и латыни. Здесь следует отметить, что название горных пород с окончанием на -ит в английском языке будут иметь окончание -ite, а название болезней с тем же окончанием будут иметь окончание -itis. Ретинит - retinite (геол.) ретинит, янтароподобная смола; retinitis (мед.) воспаление сетчатки. Гепатит - hepatite (геол.) - минерал, одна из разновидностей барита, содержащая битумы; hepatitis (мед.) гепатит, воспаление печени.

Отдельно следует остановиться на образовании новых слов. Всем известны временные промежутки в геологии: мезозой, кайнозой, nалеозой - the Mesozoic, the Cenozoic, the Paleozoic. Затем наукой был введен антропоген - the Anthropogene (Holocene). А в 1988 г. профессор Г. И. Тер-Степанян выделяет новый раздел техноген - the Technogene (по аналогии $\mathrm{c}$ the Anthropogene). То же и с пятеричным периодом the Quinary (по аналогии с the Tertiary и the Quarternary) [4, с. 1-3].

В зависимости от употребления по-разному переводится слово brine. Brine для геологической части текста необходимо переводить, как «рассол» (природная вода, содержащая растворённые минеральные вещества в повышенных концентрациях). А для медицинской части правильным будет перевод «соляной раствор» (раствор солей для медицинского применения).

Особое внимание следует уделить названиям химических элементов, которые пришли из латыни: бор - boron (не путать с bore - отверстие); бром - bromine; хлор- chlorine; фтор - fluorine.

При переводе медико-геологических текстов часто встречаются слова, которые и на первый взгляд могут переводиться одним и тем же словом. Например, слово deposit для обозначения месторождения, залежи, проявления. Но месторождение - это природное скопление полезного ископаемого. Залежь можно также назвать месторождением, но масштабность залежи меньше. Проявление и того меньше по объему. Поэтому в переводе можно сделать разграничение и в особенности, если все слова употребляются в одном тексте: field, deposit, occurrence, manifestation, соответственно. Отдельно рассматриваем слово «отложения», которые в геологии и медицине переводятся по-разному: донные отложения - sea-floor/bottom sediments, а вот отложения зубного камня - dental deposits [3, с. 5-8].

В третьем подблоке должны быть представлены практические задания и упражнения на отработку полученных знаний и усвоение 
лексического и грамматического материала. Это могут быть, как уже говорилось, блии-сочинения и письменные блии-переводы задания на перевод интернационализмов, грамматические упражнения на употребление страдательного залога, а также сочетание модальных глаголов с инфинитивом в страдательном залоге [1, с. 19, 36, 40].

Результатом применения вышеизложенных рекомендаций по обучению согласно представленной методике являются прикладные компетенции, позволяющие выпускникам применить полученные в процессе обучения знания и умения в области перевода в любой из сфер экономической деятельности человека и стать востребованными специалистами на конкурентом рынке труда. [1, с. 24].

\title{
Литература:
}

1. Парахина А. В. Пособие по переводу технических текстов с английского языка на русский: Для сред. спец. учеб. заведений. 3-е изд., доп. - М.: Высш. школа, 1982. С. 19-40.

2. Чернавина Л. И. Перевод научно-технической литературы. М.: ВЦП, 1978. С. 23-27.

3. Парфимович О. В. Доклад на тему «Медицинская геология одно из новых направлений научного перевода» на международной переводческой конференции «Translation Forum Russia» https://tconference.ru/itogi-translation-forum-russia-2019-2/ - СанктПетербург, 2019. С. 5-8.

4. Rudko G. Technogene As a New Stratigraphic Unit. Human Activity in Technogene. - Riga: LAP Lambert Academic Publishing, 2018. P. 1-3.

DOI https://doi.org/10.30525/978-9934-26-039-1-99

\section{ВИКОРИСТАННЯ ЕФЕКТИВНИХ ФОРМ І МЕТОДІВ ОН-ЛАЙН НАВЧАННЯ У ВИКЛАДАННІ ДИСЦИПЛІНИ «ПРАКТИЧНИЙ КУРС ОСНОВНОЇ ІНОЗЕМНОЇ МОВИ»}

\author{
Плахотнюк Н. П. \\ кандидат педагогічних наук,
}

старший викладач кафедри теоретичної і прикладної лінгвістики

Державного університету «Житомирська політехніка» м. Житомир, Украӥна

В умовах всесвітньої пендемії перед закладами вищої освіти постала проблема організації он-лайн навчання студентів. Серед пріорітетних 